\title{
Endodontic infections increase leukocyte and lymphocyte levels in the blood
}

\author{
Renata Oliveira Samuel ${ }^{1,2}$ • João Eduardo Gomes-Filho ${ }^{1}$ Mariane Maffei Azuma ${ }^{1,3}$. \\ Dóris Hissako Sumida ${ }^{4}$ - Sandra Helena Penha de Oliveira ${ }^{4}$. \\ Fernando Yamamoto Chiba ${ }^{4}$ - Suely Regina Mogami Bomfim ${ }^{5}$ - Paulo César Ciarlini ${ }^{5}$. \\ Luis Gustavo Narciso ${ }^{5}$. Luciano Tavares Angelo Cintra ${ }^{1}$
}

Received: 14 December 2015 / Accepted: 27 September 2017 / Published online: 11 October 2017

(C) Springer-Verlag GmbH Germany 2017

\begin{abstract}
Objectives The aim of this study was to determine whether the presence of single or multiple apical periodontitis (AP) alters blood cell counts and cytokine production.

Material and methods Thirty rats were divided into three groups: a control group comprising rats without AP, a group called $1 \mathrm{AP}$ comprising rats with $\mathrm{AP}$ in one tooth, and a group called 4AP comprising rats with AP in four teeth. Endodontic infection was induced by pulp exposure of the first right maxillary molar in the 1AP group or by exposing the first and second right maxillary and mandibular molars in the 4AP group. A blood count and cytokine levels were obtained 30 days after infection by collecting blood by cardiac puncture. The maxillae were dissected and stained with hematoxylin and eosin to evaluate the inflammatory infiltrate. The data were tabulated and subjected to statistical analysis $(P<0.05)$. Results Histological analysis showed a predominance of mononuclear inflammatory cells. In blood, significant increase of leukocytes, lymphocytes, and tumor necrosis factor
\end{abstract}

Luciano Tavares Angelo Cintra

lucianocintra@foa.unesp.br

1 Department of Endodontics, School of Dentistry, São Paulo State University (Unesp), R: José Bonifácio, 1193, Araçatuba, São Paulo, Brazil

2 Department of Clinical Dentistry, Dental School, UNIUBE-Universidade de Uberaba, Uberaba, MG, Brazil

3 Department of Endodontics, Ingá University Center, UNINGÁ, Rod. PR 317, 6114 - Parque Industrial 200, Maringá, PR 87035-510, Brazil

4 Department of Basic Sciences, School of Dentistry, São Paulo State University (Unesp), Araçatuba, SP, Brazil

5 Department of Veterinary Clinical Laboratory, School of Veterinary Medicine, São Paulo State University (Unesp), Araçatuba, SP, Brazil alpha (TNF- $\alpha$ ) in 4AP compared with the control and 1AP groups $(P<0.05)$ was observed. In addition, significant decrease of interleukin-4 (IL-4) in 1AP and 4AP groups compared with the control was observed $(P<0.05)$.

Conclusions In the rat model, the presence of multiple AP can affect health by increasing lymphocyte and TNF- $\alpha$ levels in the blood.

Clinical relevance The presence of endodontic infections can interfere with the blood profile, altering systemic health.

Keywords Apical periodontitis · Leukocytes ·

Lymphocytes $\cdot$ Blood count

\section{Introduction}

Infection of endodontic origin is very common in the general population. They are primarily characterized by the presence of harmful agents and a complex immune system that functions by (i) the neutralization of bacteria and their products and (ii) the induction of tissue repair [1]. However, the equilibrium of this process depends on the presence of mediators, which activate and inhibit inflammation to avoid deleterious effects [2]. These effects, which are stimulated by high bacterial load [1] or by diseases that affect the immune system, elevate levels of the mediators in the blood and activate inflammation [3, 4].

The increase of inflammatory cells and mediators in the blood potentiates local inflammatory processes, such as apical periodontitis (AP) [5], and may accelerate the pathogenesis of autoimmune diseases such as rheumatoid arthritis and psoriasis [6]. Therefore, it has been suggested that a bidirectional relationship exists between dental infections and systemic health $[7,8]$.

Previous studies have shown that infections of dental origin, especially periodontal disease, have a direct relationship with autoimmune diseases $[3,4]$ and potentiate metabolic upsets by 
increasing glycosylated hemoglobin [4, 9], triglycerides [10, 11], inflammatory cells, mediators [4], and oxidative stress [12]. However, few studies have been conducted with respect to infection of endodontic origin. It was previously reported that the presence of AP or periodontal disease localized in one tooth led to slight alterations in the blood $[3,4,13]$. However, when periodontal disease was concomitant with AP, significant alterations in blood and organs were observed [13, 14]. To date, there are few evidences that endodontic infection alone can lead to alterations $[15,16]$. Thus, it is possible that the presence of more than one tooth with AP may lead to a significant alteration in inflammatory cells and mediators, as observed previously, when proinflammatory cytokines and nitric oxide were evaluated [17].

The blood count is a highly reliable test and has been used for blood evaluation in several studies [13, 18, 19]. It is possible to evaluate several blood parameters such as the levels of erythrocytes, leukocytes, neutrophils, and lymphocytes. Those cells are directly related to the presence of infection such as AP [13]. Regarding inflammatory mediators, tumor necrosis factor alpha (TNF- $\alpha$ ) is a pro-inflammatory cytokine related with AP progression [20]. On the other hand, interleukin-4 (IL-4) has been described as a potential protective mediator suppressing proinflammatory responses [21]. Thus, those cytokines may be related to the imbalance of bone metabolism in the periapical area, as well as to the blood alterations in consequence of AP.

Thus, the aim of this study was to assess blood counts and TNF- $\alpha$ and IL- 4 serum levels from rats with single or multiple AP to determine the alterations in the blood profile linked to AP.

\section{Material and methods}

\section{Experimental animals}

The experimental protocol was approved by the institutional ethics committee and was conducted in accordance with the relevant guidelines of the Ethics Committee on Animal Use (201400108). Three-month-old male Wistar rats weighing 250-280 g were housed in a temperature-controlled room $\left(25^{\circ} \mathrm{C}\right)$ with a 12-h dark/light cycle. Food and water were provided ad libitum.

\section{Induction of AP}

The rats were divided into three groups of ten rats each: a control group - rats without AP, a group called $1 \mathrm{AP}$ - rats with $\mathrm{AP}$ on the first molar of the right maxillae, and a group called $4 \mathrm{AP}$ - rats with AP on the first and second right maxillary and mandibular molars.

Anesthesia was administered to each rat in the experimental groups by an intraperitoneal injection of xylazine $(13 \mathrm{mg} / \mathrm{kg}$; Coopazine; Coopers Ltd. Brazil, São Paulo, Brazil) combined with ketamine $(87 \mathrm{mg} / \mathrm{kg}$; Vetaset; Fort Dodge Animal Health Ltd., São Paulo, Brazil). For the induction of AP, the pulps of the molars were exposed on the mesial surface by using a surgical round bur of $0.1 \mathrm{~mm}$ diameter (Broca LN Long Neck, Dentsply Maillefer Ind. e Com. Ltda, Petrópolis, Brazil).

\section{Blood sample collection, determination of hematologic parameters, and assessment of serum levels of IL-4 and TNF- $\alpha$}

After 30 days, the rats were again anesthetized as previously described and a cardiac puncture was performed to collect $5 \mathrm{~mL}$ blood from each subject. The samples were collected in ethylenediaminetetraacetic acid (EDTA), mixed, and immediately transferred to a technician, who was blinded to the case status, for processing. The following parameters were determined using an automated analyzer (ABX Micros ABC Vet; Horiba ABX Diagnostics, Montpellier, France): red blood cell concentration; packed cell volume (also known as hematocrit); mean corpuscular hemoglobin level; mean corpuscular volume (MCV); mean corpuscular hemoglobin concentration (MCHC); and leukocyte, neutrophil, lymphocyte, monocyte, basophil, and eosinophil counts.

Serum cytokine levels were assessed by performing capture enzyme-linked immunosorbent assays (ELISAs) using commercial kits (rat TNF ELISA set BD OptEIA, cat \#558535; BD Biosciences, San Diego, CA; rat IL-4 PICOKINETM ELISA kit \#EK0406; Boster Biological Technology, Pleasanton, CA), according to the manufacturers' instructions. Next, the values for each of those hematologic parameters were subjected to analysis of variance followed by the Tukey's test $(P<0.05)$. The cytokine levels were subjected to Kruskall-Wallis test with Dunn's posttest $(P<0.05)$.

\section{Tissue processing and morphometric evaluation}

After blood sample collection, the rats were sacrificed using an overdose of anesthetic solution. Their maxillae were removed and subjected to conventional histological processing, as described in a previous study [13].

The extent and severity of the inflammation were evaluated by examining the inflammatory infiltrate. The average number of cells per field in the inflammatory infiltrate and the extent of the inflammation beyond either apical foramen were considered. For each experimental group, the number of cells in the infiltrate was calculated as the average of 10 separate fields (400× magnification), according to the method described in a previous study [4]. The severity of the inflammation was evaluated by assigning one of the following grades to the infiltrate: absent $(0$ to few inflammatory cells: score 1$)$, mild $(<25$ cells: score 2$)$, moderate ( $25-125$ cells: score 3$)$, and severe ( $>125$ cells: score 4). Analyses were performed blindly by a single calibrated operator. Inflammation scores were statistically analyzed (Kruskal-Wallis test, $P<0.05$ ) [4]. 
Table 1 Mean and standard deviation of blood cell parameters

Hematologic parameters Groups $($ mean $\pm \mathrm{SD}) *$

\begin{tabular}{llll}
\cline { 2 - 4 } & Control group & $1 \mathrm{AP}$ & \multicolumn{1}{l}{4 AP } \\
\hline Leukocytes $\left(10^{2} / \mu \mathrm{L}\right)$ & $58.54 \pm 0.83^{\mathrm{a}}$ & $65.62 \pm 1.53^{\mathrm{a}}$ & $79.69 \pm 0.81^{\mathrm{b}}$ \\
Lymphocytes $\left(10^{2} / \mu \mathrm{L}\right)$ & $39.39 \pm 7.65^{\mathrm{a}}$ & $43.50 \pm 8.39^{\mathrm{a}}$ & $56.70 \pm 9.56^{\mathrm{b}}$ \\
Neutrophils $\left(10^{2} / \mu \mathrm{L}\right)$ & $18.42 \pm 4.34^{\mathrm{a}}$ & $19.35 \pm 3.86^{\mathrm{a}}$ & $20.86 \pm 5.31^{\mathrm{a}}$ \\
Hematocrit & $45.33 \pm 2.92^{\mathrm{a}}$ & $44.85 \pm 2.11^{\mathrm{a}}$ & $43.30 \pm 1.70^{\mathrm{a}}$ \\
Hemoglobin & $15.45 \pm 0.91^{\mathrm{a}}$ & $14.95 \pm 0.52^{\mathrm{a}}$ & $14.50 \pm 0.27^{\mathrm{a}}$ \\
MCV (fL) & $54.49 \pm 0.74^{\mathrm{a}}$ & $53.50 \pm 1.76^{\mathrm{a}}$ & $52.79 \pm 1.11^{\mathrm{a}}$ \\
\hline
\end{tabular}

* Different letters indicate significant statistical differences in lines $(P<0.05)$

\section{Results}

\section{Blood count}

The results of the blood tests are shown in Table 1. Among the inflammatory cells, a significant increase in leukocytes and lymphocytes was observed in 4AP compared with the control $(P<0.05)$. Lymphocytes and leukocytes increased to 43.9 and $36 \%$ in 4AP, respectively. Monocytes and neutrophils also increased to 23 and $13 \%$, respectively, in 4AP compared with the control; however, this difference was not significant. Mean corpuscular volume (MCV), mean corpuscular hemoglobin concentration (MCHC), eosinophils, erythrocytes, and packed cell volume (also known as hematocrit) showed no significant difference $(P>0.05)$ (Table 1$)$.

\section{Serum levels of IL-4 and TNF- $\alpha$}

Serum levels of IL-4 and TNF- $\alpha$ are shown in Table 2. Serum level of TNF- $\alpha$ was higher in the 4AP group compared with $1 \mathrm{AP}$ and control groups $(P<0.05)$. In addition, the levels of IL-4 in the $1 \mathrm{AP}$ and 4AP groups were lower compared to control group $(P<0.05)$.

\section{Histologic findings}

Representative hematoxylin-eosin-stained sections are shown in Fig. 1. Thirty days after AP induction, the pulp showed total necrosis and AP was established in the 1AP and 4AP groups. The AP was exclusively restricted to the periapex region. Moreover, the AP was composed primarily of neutrophils (polymorphonuclears) and mononuclear cells and comprised moderate inflammatory infiltrate in most samples (Table 2). There was no difference between the 1AP and 4AP groups. In the control group, no sample showed inflammatory infiltrates, and all samples received a score of 0 (Table 3 ).

\section{Discussion}

The present study determined whether single or multiple AP leads to blood alterations. Our results confirmed that endodontic infections in multiple teeth can lead to IL-4 level decrease in blood but increase lymphocyte and TNF- $\alpha$ levels. The histologic features also confirmed this relationship: in addition to the increased levels of lymphocytes in the blood, there were increased levels of lymphocytes in response to bacterial infection in AP in the 1AP and 4AP groups.

The prevalence of lymphocytes in AP is explained by the experimental period of 30 days, since at this stage the lesion has the characteristics of chronic inflammation [22]. In a previous study, we observed similar results in rats with periodontal disease associated with AP [13]. Although there was no significant increase in the presence of dental infection in two teeth, there was an increase of $61 \%$ in the average number of leukocytes in the group with AP concomitant with periodontal disease compared with those without dental infections [13].

The increased numbers of inflammatory cells resulting from AP may activate and enhance the deleterious effects of autoimmune diseases. They may also activate inflammatory mediators and increase oxidative stress, exacerbating inflammation in different foci throughout the body [23]. Once the biological pathways that activate inflammation and autoimmunity are the same, the presence of AP can increase the deleterious effects of autoimmune diseases, and the pathogenesis of autoimmune disease can also potentiate the effects of AP in a bidirectional relationship [24, 25]. In this context, we found that the presence of multiple APs increased the level of the pro-inflammatory cytokine TNF- $\alpha$ while it decreased the level of the protective mediator IL-4 in rat's blood.
Table 2 Serum levels of IL-4 and $\mathrm{TNF}-\alpha$ (in $\mathrm{pg} / \mathrm{mL}$ )

\begin{tabular}{llll}
\hline Cytokines & \multicolumn{2}{l}{ Groups (mean, min-max values)* } & \\
\cline { 2 - 4 } & Control group & 1AP & 4AP \\
\hline TNF- $\alpha$ & $44.87(26.00-47.15)^{\mathrm{a}}$ & $46.35(22.48-66.89)^{\mathrm{a}}$ & $262.65(115.63-310.89)^{\mathrm{b}}$ \\
$\mathrm{IL}-4$ & $26.19(24.27-28.50)^{\mathrm{a}}$ & $22.26(18.02-26.44)^{\mathrm{b}}$ & $22.39(16.10-25.24)^{\mathrm{b}}$ \\
\hline
\end{tabular}

Control group rats without apical periodontitis, $1 A P$ rats with apical periodontitis in 1 tooth, $4 A P$ rats with apical periodontitis in 4 teeth, $I L$ interleukin, $T N F$ - $\alpha$, tumor necrosis factor alpha

*Different letters indicate significant statistical differences in lines $(P<0.05)$ 

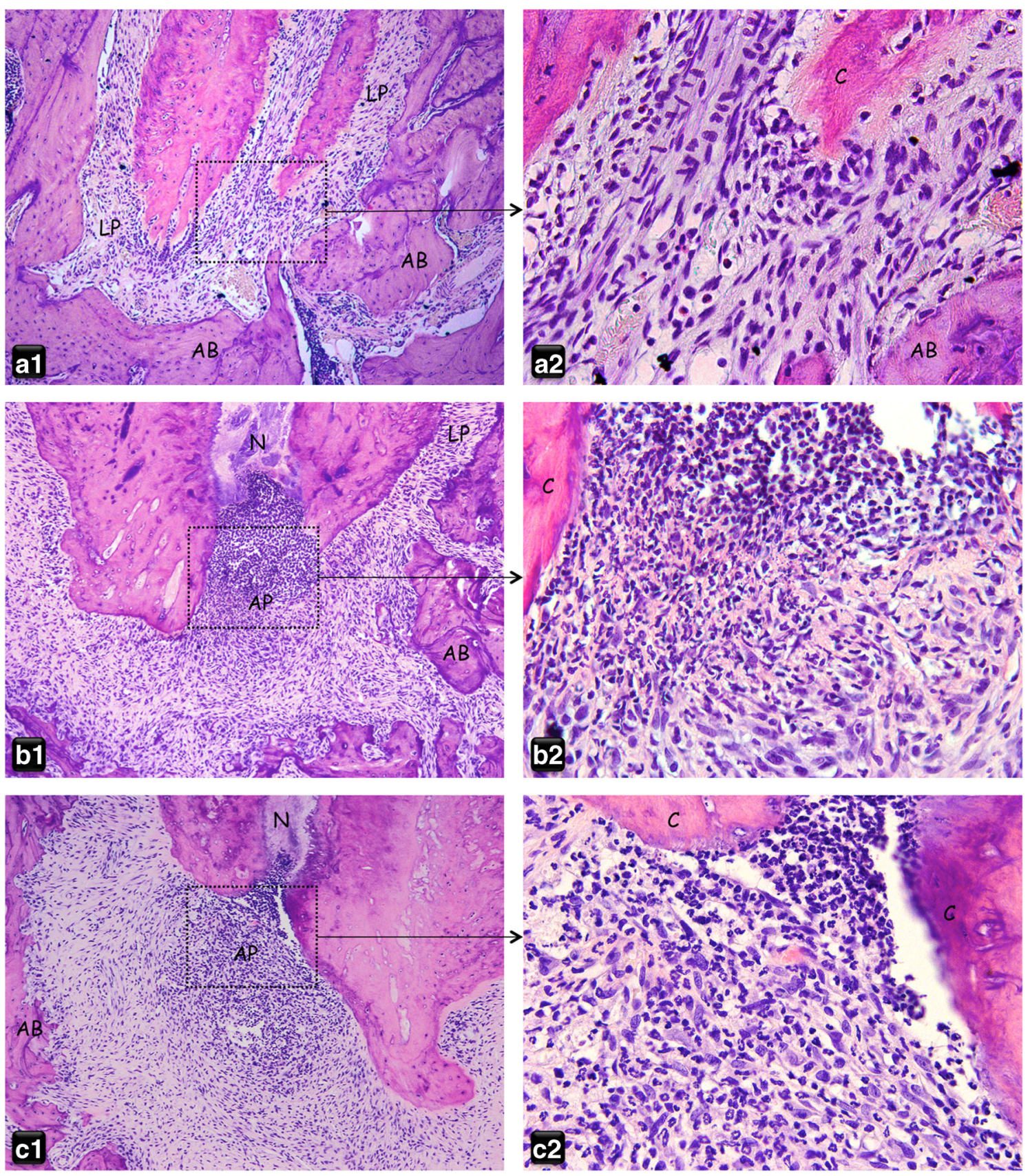

Fig. 1 Histological observations of the control group: (a1,a2). Photomicrographs showing the periapical area with normal features and an absence of inflammatory infiltration at the apical and periapical regions (hematoxylin, 100× and 400×). Representative histological findings 30 days following apical periodontitis (AP) induction:

Serum increase of TNF- $\alpha$ in the presence of AP was demonstrated in another study [17]. Both in AP and in periodontal disease, TNF- $\alpha$ acts in the process of bone resorption, stimulating clastic cells and other mediators that activate inflammation [26]. Moreover, it is known that TNF- $\alpha$ may potentiate the pathogenesis of autoimmune diseases, such as cardiovascular diseases and diabetes $[27,28]$. In diabetes mellitus, e.g., insulin resistance was associated with higher level of TNF- $\alpha$ in rats (b1,b2,c1,c2). A sagittal section of a first molar that shows moderate inflammatory cell infiltration near the tooth apex region, severe disorganization of the periodontal ligament, and large areas of bone resorption (hematoxylin, $100 \times$ and $400 \times$ ). PL periodontal ligament, AB alveolar bone, $\mathrm{C}$ cementum, $\mathrm{N}$ total necrosis, $\mathrm{AP}$ apical periodontitis with periodontal disease when compared to diabetic rats without periodontal disease and lower TNF- $\alpha$ level [29].

IL-4 is an immune-regulatory protein secreted by activated Th2 lymphocytes and acts of physiological processes in the organism [30]. Serum and local decreased IL-4 may be harmful. Studies show a greater process of bone resorption in periodontal disease associated with a reduction in IL-4 level [31, 32]. This increase of osteoclastic activity may be due to IL-4 related to the 
Table 3 Scores and median of the histological findings

\begin{tabular}{llll}
\hline Intensity of inflammatory infiltrate & \multicolumn{2}{l}{ Groups } \\
\cline { 2 - 4 } & Control group & 1AP & 4AP \\
\hline 1- absent & $10 / 10$ & $0 / 10$ & $0 / 10$ \\
2-mild & $0 / 10$ & $1 / 10$ & $0 / 10$ \\
3-moderate & $0 / 10$ & $8 / 10$ & $8 / 10$ \\
4-severe & $0 / 10$ & $1 / 10$ & $2 / 10$ \\
Median* & $1^{\mathrm{a}}$ & $3^{\mathrm{b}}$ & $3^{\mathrm{b}}$ \\
\hline
\end{tabular}

*Different letters indicate significant statistical differences in lines $(P<0.05)$

control of TNF- $\alpha$ release, i.e., the presence of IL- 4 can reduce the expression of proinflammatory cytokines, such as IL-1, IL-6, and TNF- $\alpha$ [33]. In the present study, there was decreasing on IL-4 and increasing on TNF- $\alpha$, as it occurs in some autoimmune diseases, such as cardiovascular disorders [34]. Thus, it is noted that imbalances both pro-inflammatory and anti-inflammatory mediators impair body hemostasis [34].

Confirming this bidirectional relationship, models with diabetes and oral infections, i.e., have shown that various parameters are altered in the presence of systemic diseases and periodontal and periapical lesions. These alterations include increasing on blood glucose [4], glycosylated hemoglobin [4], triglycerides [11], inflammatory mediators such as IL-17 and neutrophils [3], and insulin resistance [27]. Cardiovascular diseases have also been reported to be associated with AP [28]. Moreover, histological and radiographic analysis of the lesions has revealed a significant increase in bone loss in diabetic rats compared with nondiabetic rats with the same dental infections [3].

Our results showed that blood neutrophil levels were not significantly different between the groups. This result is consistent with a previous report, which also showed that neutrophil levels in the presence of concomitant periodontal disease and AP were not significantly different [13]. In diabetic rats with AP and concomitant periodontal disease, the lesions showed acute inflammation even at 30 days, which also led to increased levels of polymorphonuclear cells [13]. This indicates that diabetes enhances the inflammatory process. In the present study, the rats with AP were healthy. Thus, after 30 days, AP showed chronic inflammation, and lower levels of neutrophils between groups were expected, since these cells are the first line of defense [22].

In the present study, there was no significant difference in $\mathrm{MCV}$, hematocrit, and hemoglobin in the presence of AP. However, it was noticeable that all these parameters were slightly reduced in the presence of multiple AP compared with the control group. In the presence of aggressive periodontal disease, some studies have also reported a reduction of red blood cells and hemoglobin levels, suggesting that periodontal disease may be associated with the pathogenesis of mild anemia $[35,36]$. Since in the present study AP was induced in only four teeth, the difference between the groups was not significant, as observed in generalized periodontitis.

In the present study, the presence of AP in one tooth did not result in significant differences compared with uninfected rats. These data are consistent with those of a previous study [13] and were therefore expected. However, a slight increase in some parameters suggested the need for induction of infection in multiple teeth to observe significant differences, as observed in some patients. It is common for a single patient to show foci of endodontic infections in multiple teeth [37].

Experimental induction of AP in rats is a consistent method and an accepted model for studying AP [38]. The use of experimental animal model allowed to perform the study under standardized conditions where animals of the same strain, sex, and weight received the same food, experienced the same stress, and shared the same accommodation [38]. Similar study in humans would not be ideal owing to the variability of samples, which could put the results into question. In addition, blood count is an extremely reliable test and has been used in several medical evaluations and scientific studies [13, $18,19]$. For those reasons, we found it prudent to use blood count in rats to confirm the hypothesis that infection of endodontic origin may influence systemic health.

The scientific community has not extensively explored the relationship between AP and systemic health. However, the existence of this relationship in periodontal disease has been well established by several in vivo and in vitro studies [39-41]. Although both infections have a similar pathogenesis with similar bacterial profile and inflammatory process with subsequent bone resorption, the treatment of endodontic infection is still not completely seen as a holistic health promotion.

Given the results of this study, it is noted that AP can activate or enhance the deleterious effects of autoimmune diseases, owing to the significant systemic alterations that occur in the blood, such as increased lymphocyte counts and proinflammatory mediators.

\section{Conclusion}

In conclusion, the presence of multiple apical periodontitis can affect health by increasing lymphocyte and TNF- $\alpha$ levels and decreasing IL-4 levels in the blood.

Funding This study was supported by a grant (2013/23358-8) from the São Paulo Research Foundation (FAPESP), São Paulo, SP, Brazil.

\section{Compliance with ethical standards}

Conflict of interest The authors declare that they have no conflicts of interest. 
Ethical approval This article does not contain any studies with human participants performed by any authors. The animal study was approved by the Institutional Ethics Committee (CEUA 2014-00108) of Universidade Estadual Paulista, São Paulo, Brazil and conducted in accordance with ethical standards.

Informed consent For this type of study, formal consent is not required.

\section{References}

1. Márton IJ, Kiss C (2014) Overlapping protective and destructive regulatory pathways in apical periodontitis. J Endod 40:155-163. https://doi.org/10.1016/j.joen.2013

2. Garlet GP (2010) Destructive and protective roles of cytokines in periodontitis: a re-appraisal from host defense and tissue destruction viewpoints. J Dent Res 89:1349-1363. https://doi.org/10.1177/ 0022034510376402

3. Cintra LT, Samuel RO, Azuma MM, Ribeiro CP, Narciso LG, de Lima VM, Sumida DH, Coclete GA, Dezan-Júnior E, Gomes-Filho JE (2014) Apical periodontitis and periodontal disease increase serum IL-17 levels in normoglycemic and diabetic rats. Clin Oral Investig 18:2123-2128. https://doi.org/10.1007/s00784-014-11927

4. Cintra LT, Samuel RO, Facundo AC, Prieto AK, Sumida DH, Bomfim SR, Souza JC, Dezan-Júnior E, Gomes-Filho JE (2014) Relationships between oral infections and blood glucose concentrations or HbA1c levels in normal and diabetic rats. Int Endod J 47: 228-237. https://doi.org/10.1111/iej.12136

5. Marçal JR, Samuel RO, Fernandes D, de Araujo MS, Napimoga MH, Pereira SA, Clemente-Napimoga JT, Alves PM, Mattar R, Rodrigues V Jr, Rodrigues DB (2010) T-helper cell type 17/ regulatory T-cell immunoregulatory balance in human radicular cysts and periapical granulomas. J Endod 36:995-999. https://doi. org/10.1016/j.joen.2010.03.020

6. Liu Y, Yin H, Zhao M, Lu Q (2014) TLR2 and TLR4 in autoimmune diseases: a comprehensive review. Clin Rev Allergy 47:136147. https://doi.org/10.1007/s12016-013-8402-y

7. Linden GJ, Herzberg MC (2013) Periodontitis and systemic diseases: a record of discussions of working group 4 of the Joint EFP/AAP workshop on periodontitis and systemic diseases. J Periodontol 84:S20-S23. https://doi.org/10.1902/jop.2013. 1340020

8. Khalaf H, Lönn J, Bengtsson T (2014) Cytokines and chemokines are differentially expressed in patients with periodontitis: possible role for TGF- $\beta 1$ as a marker for disease progression. Cytokine 67 : 29-35. https://doi.org/10.1016/j.cyto.2014.02.007

9. Morita I, Inagaki K, Nakamura F, Noguchi T, Matsubara T, Yoshii S, Nakagaki H, Mizuno K, Sheiham A, Sabbah W (2012) Relationship between periodontal status and levels of glycated hemoglobin. J Dent Res 91:161-166. https://doi.org/10.1177/ 0022034511431583

10. Shimazaki Y, Saito T, Yonemoto K, Kiyohara Y, Iida M, Yamashita Y (2007) Relationship of metabolic syndrome to periodontal disease in Japanese women: the Hisayama Study. J Dent Res 86:271-275

11. Cintra LT, da Silva Facundo AC, Azuma MM, Sumida DH, Astolphi RD, Bomfim SR, Narciso LG, Gomes-Filho JE (2013) Pulpal and periodontal diseases increase triglyceride levels in diabetic rats. Clin Oral Investig 17:1595-1599. https://doi.org/10. 1007/s00784-012-0853-7

12. Hendek MK, Erdemir EO, Kisa U, Ozcan G (2014) Effect of initial periodontal therapy on the oxidative stress markers in gingival crevicular fluid, saliva and serum in smokers and non-smokers with chronic periodontitis. J Periodontol 17:1-17. https://doi.org/10. 1902/jop.2014.140338

13. Cintra LT, da Silva Facundo AC, Prieto AK, Sumida DH, Narciso LG, Mogami Bomfim SR, Oliveira e Silva C, Dezan-Júnior E, Gomes-Filho JE (2014) Blood profile and histology in oral infections associated with diabetes. J Endod 40:1139-1144. https://doi. org/10.1016/j.joen.2014.01.034

14. Cintra LT, Samuel RO, Prieto AK, Sumida DH, Dezan-Júnior E, Gomes-Filho JE (2017) Oral health, diabetes, and body weight. Arch Oral Biol 73:94-99. https://doi.org/10.1016/j.archoralbio. 2016.10.002

15. Pereira RF, de Oliveira da Mota MS, de Lima Coutinho Mattera MS, Tsosura TV, Chiba FY, Garbin CA, Ervolino E, Cintra LT, Okamoto MM, Machado UF, Sumida DH (2016) Periapical lesions decrease Akt serine phosphorylation and plasma membrane GLUT4 content in rat skeletal muscle. Clin Oral Investig 20: 1625-1630. https://doi.org/10.1007/s00784-015-1664-4

16. Astolphi RD, Curbete MM, Chiba FY, Cintra LT, Ervolino E, da Mota MS, Antoniali C, Garbin CA, Sumida DH (2015) Periapical lesions decrease insulin signaling in rat skeletal muscle. J Endod 41: 1305-1310. https://doi.org/10.1016/j.joen.2015.04.002

17. Cintra LT, Samuel RO, Azuma MM, de Queiróz AO, Ervolino E, Sumida DH, de Lima VM, Gomes-Filho JE (2016) Multiple apical periodontitis influences serum levels of cytokines and nitric oxide. J Endod. 42:747-751. https://doi.org/10.1016/j.joen.2016.01.022

18. Musalaiah SV, Anupama M, Nagasree M, Krishna CM, Kumar A, Kumar PM (2014) Evaluation of nonsurgical periodontal therapy in chronic periodontitis patients with anemia by estimating hematological parameters and high-sensitivity C-reactive protein levels. J Pharm Bioallied Sci 6:S64-S69. https://doi.org/10.4103/09757406.137390

19. Gaddale R, Mudda JA, Karthikeyan I, Desai SR, Shinde H, Deshpande $P$ (2014) Changes in cellular and molecular components of peripheral blood in patients with generalized aggressive periodontitis. J Investig Clin Dent. https://doi.org/10.1111/jicd.12127

20. Graves D (2008) Cytokines that promote periodontal tissue destruction. J Periodontol 79:1585-1591

21. Stein NC, Kreutzmann C, Zimmermann SP, Niebergall U, Hellmeyer L, Goettsch C, Schoppet M, Hofbauer LC (2008) Interleukin-4 and interleukin-13 stimulate the osteoclast inhibitor osteoprotegerin by human endothelial cells through the STAT6 pathway. J Bone Miner Res 23:750-758. https://doi.org/10.1359/ jbmr.080203

22. Liu L, Peng B (2013) The expression of macrophage migration inhibitory factor is correlated with receptor activator of nuclear factor kappa B ligand in induced rat periapical lesions. J Endod 39:984-989. https://doi.org/10.1016/j.joen.2013.03.001

23. Bian Z, Guo Y, Ha B, Zen K, Liu Y (2012) Regulation of the inflammatory response: enhancing neutrophil infiltration under chronic inflammatory conditions. J Immunol 188:844-853. https://doi.org/10.4049/jimmunol.1101736

24. Gomes MS, Blattner TC, Sant'Ana Filho M, Grecca FS, Hugo FN, Fouad AF, Reynolds MA (2013) Can apical periodontitis modify systemic levels of inflammatory markers? A systematic review and meta-analysis. J Endod 39:1205-1217. https://doi.org/10.1016/j. joen.2013.06.014

25. Gomes MS, Hugo FM, Hilgert JB, Sant'Ana Filho M, Padilha DMP, Simonsick EM (2015) Apical periodontitis and incident cardiovascular events in the Baltimore Longitudinal Study of Aging. Int Endod J. https://doi.org/10.1111/iej.12468

26. Yu Y, Yang D, Qiu L, Okamura H, Guo J, Haneji T (2014) Tumor necrosis factor- $\alpha$ induces interleukin-34 expression through nuclear factor- $\mathrm{kB}$ activation in MC3T3-E1 osteoblastic cells. Mol Med Rep 10:1371-1376. https://doi.org/10.3892/mmr.2014.2353

27. Astolphi RD, Curbete MM, Colombo NH, Shirakashi DJ, Chiba FY, Prieto AK, Cintra LT, Bomfim SR, Ervolino E, Sumida DH 
(2013) Periapical lesions decrease insulin signal and cause insulin resistance. J Endod 39:648-652. https://doi.org/10.1016/j.joen. 2012.12.031

28. Cotti E, Dessì C, Piras A, Flore G, Deidda M, Madeddu C, Zedda A, Longu G, Mercuro G (2011) Association of endodontic infection with detection of an initial lesion to the cardiovascular system. J Endod 37:1624-1629. https://doi.org/10.1016/j.joen.2011.09.006

29. Colombo NH, Shirakashi DJ, Chiba FY, Coutinho MS, Ervolino E, Garbin CA, Machado UF, Sumida DH (2012) Periodontal disease decreases insulin sensitivity and insulin signaling. J Periodontol 83: 864-870. https://doi.org/10.1902/jop.2011.110349

30. Swain SL, Weinberg AD, English M, Huston G (1990) IL-4 directs the development of Th2-like helper effectors. J Immunol 145:3796-3806

31. Ribeiro FV, de Mendonça AC, Santos VR, Bastos MF, Figueiredo LC, Duarte PM (2011) Cytokines and bone-related factors in systemically healthy patients with chronic periodontitis and patients with type 2 diabetes and chronic periodontitis. J Periodontol 82: 1187-1196. https://doi.org/10.1902/jop.2011.100643

32. Behfarnia P, Birang R, Pishva SS, Hakemi MG, Khorasani MM (2013) Expression levels of th-2 and th-17 characteristic genes in healthy tissue versus periodontitis. J Dent (Tehran) 10:23-31

33. Gemmell E, Marshall RI, Seymour GJ (1997) Cytokines and prostaglandins in immune homeostasis and tissue destruction in periodontal disease. Periodontol 2000 14:112-143

34. Ruiz-Canela M, Bes-Rastrollo M, Martínez-González MA (2016) The role of dietary inflammatory index in cardiovascular disease, metabolic syndrome and mortality. Int J Mol Sci 17:8. https://doi. org/10.3390/ijms 17081265

35. Agarwal N, Kumar VS, Gujjari SA (2009) Effect of periodontal therapy on hemoglobin and erythrocyte levels in chronic generalized periodontitis patients: an interventional study. J Indian Soc Periodontol 13:6-11. https://doi.org/10.4103/0972-124X.51887

36. Anand PS, Sagar DK, Ashok S, Kamath KP (2013) Association of aggressive periodontitis with reduced erythrocyte counts and reduced hemoglobin levels. J Periodontal Res 49:719-728. https:// doi.org/10.1111/jre.12154

37. Domínguez-Sánchez B, López-López J, Jané-Salas E, CastellanosCosano L, Velasco-Ortega E, Segura-Egea JJ (2015) Glycated hemoglobin levels and prevalence of apical periodontitis in type 2 diabetic patients. J Endod 41:601-606. https://doi.org/10.1016/j. joen.2014.12.024

38. Clause BT (1993) The Wistar rat as a right choice: establishing mammalian standards and the ideal of a standardized mammal. J Hist Biol 26:329-349

39. Ide R, Hoshuyama T, Wilson D, Takahashi K, Higashi T (2011) Periodontal disease and incident diabetes: a seven-year study. J Dent Res 90:41-46. https://doi.org/10.1177/0022034510381902

40. D'Aiuto F, Suvan J (2012) Obesity, inflammation, and oral infections: are microRNAs the missing link? J Dent Res 91:5-7. https:// doi.org/10.1177/0022034511427164

41. Jia R, Kurita-Ochiai T, Oguchi S, Yamamoto M (2013) Periodontal pathogen accelerates lipid peroxidation and atherosclerosis. J Dent Res 92:247-252. https://doi.org/10.1177/0022034513475625 